\title{
Identifikasi Personal Berdasarkan Geometri Citra Punggung Tangan Kiri Menggunakan Metode Learning Vector Quantization
}

\section{Personal Identification Based on Back of Left Hand Geometry Using Learning Vector Quantization}

\author{
Muhammad Fandi Nurdiansyah ${ }^{1}$, Indah Susilawati ${ }^{2}$ \\ Program Studi Teknik Informatika. Fakultas Teknologi Informasi, Universitas Mercu Buana Yogyakarta \\ Jl. Wates Km. 10 Yogyakarta 55753, Indonesia \\ Email: muhammadfnd90@gmail.com ${ }^{1}$, indah_nik@yahoo.co.id ${ }^{2}$
}

\begin{abstract}
ABSTRAK
Geometri Tangan (Hand Geometry), merupakan biometrika yang relatif baru, yang memiliki karakteristik unik seperti lebar telapak tangan, luas tangan, dan panjang jari. Ukuran geometri tangan seseorang cenderung berbeda dengan tangan milik orang lain. Keunikan inilah yang merupakan ciri setiap tangan. Sistem identifikasi merupakan proses pencocokan citra punggung tangan kiri yang diuji dengan suatu citra punggung tangan kiri yang diklaim. Hasilnya adalah suatu keputusan apakah citra punggung tangan kiri yang diuji milik personal yang sah (genuine user) atau tidak sah (imposter user). Proses perhitungan ukuran panjang jari, lebar tangan, dan luas tangan memegang peranan penting terhadap keberhasilan identifikasi.

Tujuan utama penelitian adalah pengembangan program identifikasi personal berdasarkan geometri citra punggung tangan kiri dengan menghitung luas tangan, lebar tangan, dan panjang jari. Panjang jari diperoleh dengan metode pencarian titik puncak jari. Untuk identifikasi geometri citra punggung tangan kiri dalam penelitian ini menggunakan Jaringan Syaraf Tiruan metode Learning Vector Quantization (LVQ). Metode ini akan menghitung jarak antara bobot awal dengan data pelatihan, sehingga pada akhir iterasi akan ditemukan bobot akhir untuk setiap kelas. Hasil pengujian menunjukkan bahwa keberhasilan identifikasi personal mencapai kinerja setinggi $85,71 \%$.
\end{abstract}

Kata Kunci: pungung tangan kiri; biometrika; hand geometry; LVQ

\begin{abstract}
Hand Geometry is a relatively new biometrics, which has unique characteristics such as the width of the palm, the width of the hand, and the length of the finger. The size of a person's hand geometry tends to be different from that of someone else's. This uniqueness is what characterizes every hand. The identification system is the process of matching the image of the back of left hand tested with a claimed left hand's back image. The result is a decision whether the image tested belongs to a legal person (genuine user) or unauthorized one (imposter user). The process of measuring the length of fingers, the width of the hands, and the width of the hands plays an important role to the success of the identification. The main objective of the study is the development of a personal identification program based on the geometry of the image of the back of left hand by calculating the width of the hand, the width of the hand, and the length of the finger. The finger length is obtained by finding the finger tip search method. The study using Artificial Neural Network Learning Vector Quantization (LVQ) to identify the image based on the three geometries. This method will calculate the distance between the initial weights and the training data to find the final weight for each class. The study results show that the identification performance achieved as high as $85.71 \%$.
\end{abstract}

Keywords: back of left hand; biometrics; hand geometries; $L V Q$ 


\section{PENDAHULUAN}

Penggunaan kunci atau kartu sebagai tanda pengenal memiliki beberapa kelemahan dikarenakan mudah hilang atau bahkan dicuri, dapat digunakan secara bersamaan dan mudah diduplikasi. Demikian juga dengan userid dan password. Permasalahan yang ditimbulkan pada penggunaan userid dan password adalah cukup mudah untuk lupa dan beberapa password mudah diperkirakan. Di lain pihak, biometrika menggunakan karakteristik unik dari fisiologis manusia. Biometrika sifatnya tidak mudah hilang, tidak dapat digunakan secara bersamasama, dan sulit untuk diduplikasi. Kelebihankelebihan inilah yang menyebabkan biometrika banyak digunakan untuk sistem pengenalan seseorang secara otomatis baik untuk sistem identifikasi maupun verifikasi.

Geometri tangan adalah struktur geometri tangan seseorang seperti lebar jari tangan, lebar telapak tangan dan panjang jari tangan. Pemakaian geometri tangan sangat efektif dan mudah digunakan karena bentuk tangan yang unik untuk setiap orang dan tidak membutuhkan alat pengenalan yang rumit. Namun untuk membaca struktur geometri tangan dibutuhkan alat akuisisi yang memiliki ukuran besar. Penggunaan tangan kiri sebagai obyek citra akan membuat sistem ini lebih efektif, karena tangan kiri akan lebih sedikit digunakan dalam kegiatan sehari-hari sehingga tangan kiri akan mengalami perubahan yang cukup sedikit dibandingkan dengan tangan kanan, oleh karena itu dipilihlah tangan kiri sebagai obyek citra. Dalam penelitian ini digunakan Learning Vector Quantization untuk melakukan identifikasi personal berdasarkan geometri punggung tangan kiri.

\section{TINJAUAN PUSTAKA}

Edi Satriyanto dan Mohammad Syafi'i Ari Hanggara (2009), dalam penelitiannya yang berjudul "Penerapan LVQ Neural Network pada Absensi Jarak Jauh Menggunakan Geometri Tangan Secara Online", membangun sistem absensi pegawai jarak jauh dengan identifikasi pegawai berdasarkan geometri tangannya menggunakan web camera sebagai mesin absensinya di semua komputer yang terhubung ke jaringan komputer.

Antonius Siswanto dan Pernantin Tarigan, Fahmi (2003), melakukan penelitian yang berjudul "Perancangan Sistem Verifikasi Biometrik Tangan Tanpa Kontak dengan Ukuran Geometri Relatif". Dalam penelitian ini dirancang sistem yang dapat menangani masalah posisi tangan yang bervariasi terhadap kamera, yang menyebabkan variasi ukuran geometri tangan antara sampel-sampel citra yang diambil pada waktu yang berbeda untuk orang yang sama. Menggunakan ukuran geometri relatif sebagai acuan dalam pengenalan pola pada proses pencocokkannya, yang menggunakan jaringan saraf tiruan algoritma backpropagation.

Retno Ardhaningtyas Andari (2014), dalam penelitiannya berjudul "Analisis Sistem Verifikasi dengan Menggabungkan Biometrika Telapak Tangan dan Geometri Tangan" menganalisis sistem verifikasi dengan menggabungkan biometrik garis tangan dan geometrik tangan sebagai sistem biometrika multimodal yang menggabungkan biometrika telapak tangan dan geometrik untuk keperluan verifikasi.

Suprapto (2011), pada penelitian berjudul "Pengenalan Geometri Tangan dengan Metode Neural Network Kohonen SOM" dalam membuat sistem identifikasi seseorang berdasar geometri tangan menggunakan metode Kohonen SOM, karena Kohonen SOM memiliki proses pengenalannya yang lebih cepat dibandingkan dengan algoritma neural network yang lain.

Santoso (2003), pada penelitiannya yang berjudul "Verifikasi Personal Berdasarkan Bentuk Geometri Tangan dengan Metode Filter Gabor", menggunakan filter gabor untuk ekstraksi ciri dengan cara mengambil vektor gabor sebagai pendefinisian informasi yang spesifik dari gambar. Hal ini dapat dibuktikan dengan tingginya nilai similarity yang didapat untuk tekstur gambar yang mirip dan nilai similiarity yang rendah untuk tekstur yang berbeda.

\subsection{Geometri Tangan}

Salah satu biometrika yang dimiliki manusia adalah geometri tangan yang menggambarkan struktur geometri tangan seseorang. Struktur ini termasuk lebar jari tangan, lebar telapak tangan, ketebalan telapak tangan, panjang jari tangan dan lainnya (Lim, 2004). Sistem identifikasi berbasis geometri tangan telah banyak digunakan; selain tekniknya relatif mudah untuk digunakan, faktor-faktor seperti cuaca atau kulit kering tidak mempengaruhi ketelitian sistem untuk identifikasi geometri tangan seseorang.

Untuk kehandalan sistem, sistem biometrika geometri tangan biasanya membutuhkan alat bantu pembacaan berupa pasak dan cermin. Pasak digunakan untuk membentuk posisi tangan yang sesuai untuk memungkinkan dibaca oleh komputer. Cermin digunakan untuk mendapatkan ciri ketebalan 
geometri tangan. Dengan begitu, alat akuisisi pada sistem biometrik geometri tangan biasanya memiliki ukuran yang besar.

Dalam penelitian ini, identifikasi personal ditentukan berdasarkan data citra punggung tangan kiri yang diakuisisi menggunakan kamera digital. Salah satu contoh citra hasil akuisisi diperlihatkan pada Gambar 1.

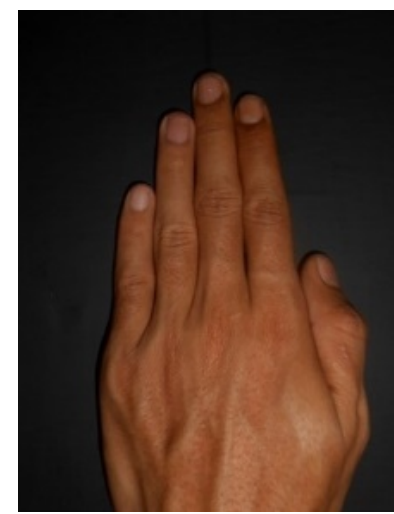

Gambar 1. Citra punggung tangan kiri

Gambar 2 memperlihatkan geometri punggung tangan kiri yang akan digunakan dalam penelitian ini, dengan $\mathrm{x} 1$ adalah lebar punggung tangan, $\mathrm{x} 2$ adalah tinggi jari manis, $\mathrm{x} 3$ adalah tinggi jari tengah, dan $\mathrm{x} 4$ adalah tinggi jari telunjuk.

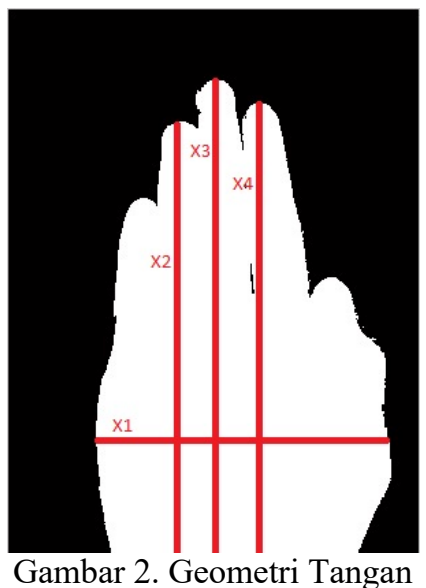

\section{METODOLOGI PENELITIAN}

Langkah-langkah penelitian yang dilakukan diperlihatkan pada Gambar 3.

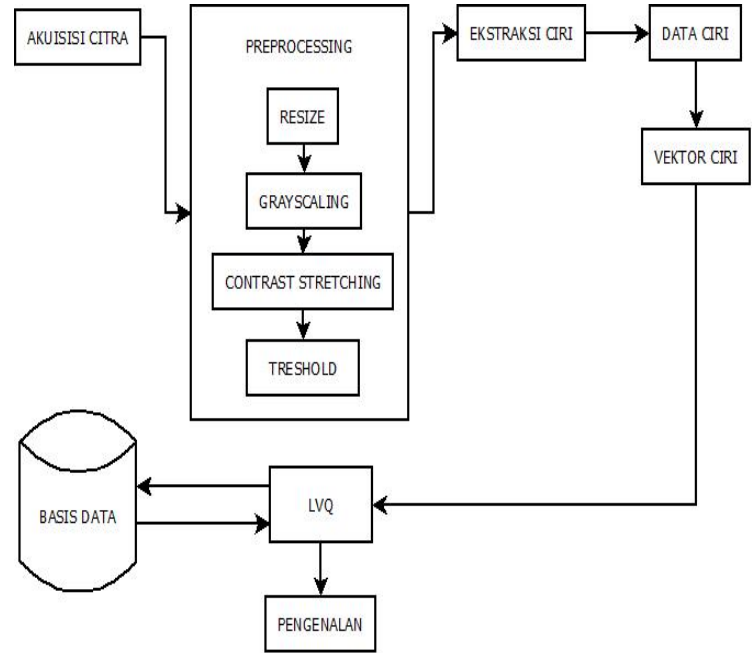

Gambar 3. Langkah penelitian

Akuisisi citra dilakukan menggunakan kamera digital. Hasil akuisisi kemudian dikenakan presprosing yang meliputi resize, gray-scalling, contrast strecthing, dan thresholding. Proses resize akan menghasilkan citra dengan ukuran 400x300 piksel. Grayscalling dilakukan menggunakan persamaan 1 .

$$
\mathrm{I}=0,299 \mathrm{R}+0,586 \mathrm{G}+0,114 \mathrm{~B}
$$

Contrast stretching digunakan untuk mendapatkan citra dengan kontras yang lebih baik daripada kontras dari citra aslinya, dengan tujuan untuk meningkatkan kinerja thresholding. Gambar 4. menunjukkan fungsi transformasi contrast stretching.

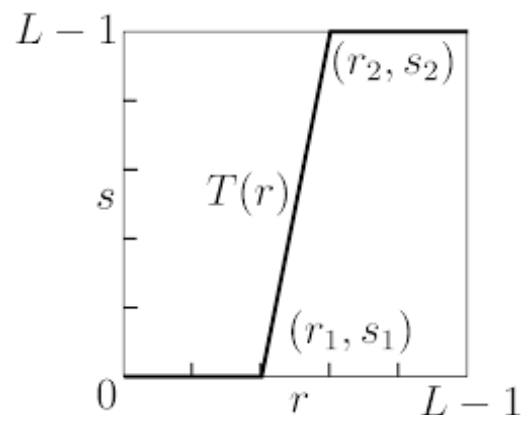

Gambar 4. Fungsi transformasi contrast stretching

Titik koordinat $\left(\mathrm{r}_{1}, \mathrm{~s}_{1}\right)$ dan $\left(\mathrm{r}_{2}, \mathrm{~s}_{2}\right)$ merupakan titik kontrol dari fungsi transformasi contrast stretching. Titik-titik tersebut dapat menunjukkan tingkat penyebaran gray level dari suatu citra. Untuk menghitung nilai hasil transformasi tersebut dapat menggunakan persamaan (2). 


$$
s=\left\{\begin{array}{lrl}
r \frac{s_{1}}{r_{1}} & \text { jika } & 0 \leq r<r_{1} \\
s_{1}+\left(r-r_{1}\right) \frac{s_{2}-s_{1}}{r_{2}-r_{1}} & \text { jika } & r_{1} \leq r<r_{2} \\
s_{2}+\left(r-r_{2}\right) \frac{(L-1)-s_{2}}{(L-1)-r_{2}} & \text { jika } & r_{2} \leq r \leq(L-1)
\end{array}\right.
$$

Citra keluaran proses contrast stretching selanjutnya dikenakan thresholding untuk memperoleh citra biner sebagai dasar penentuan ciri geometri punggung tangan.

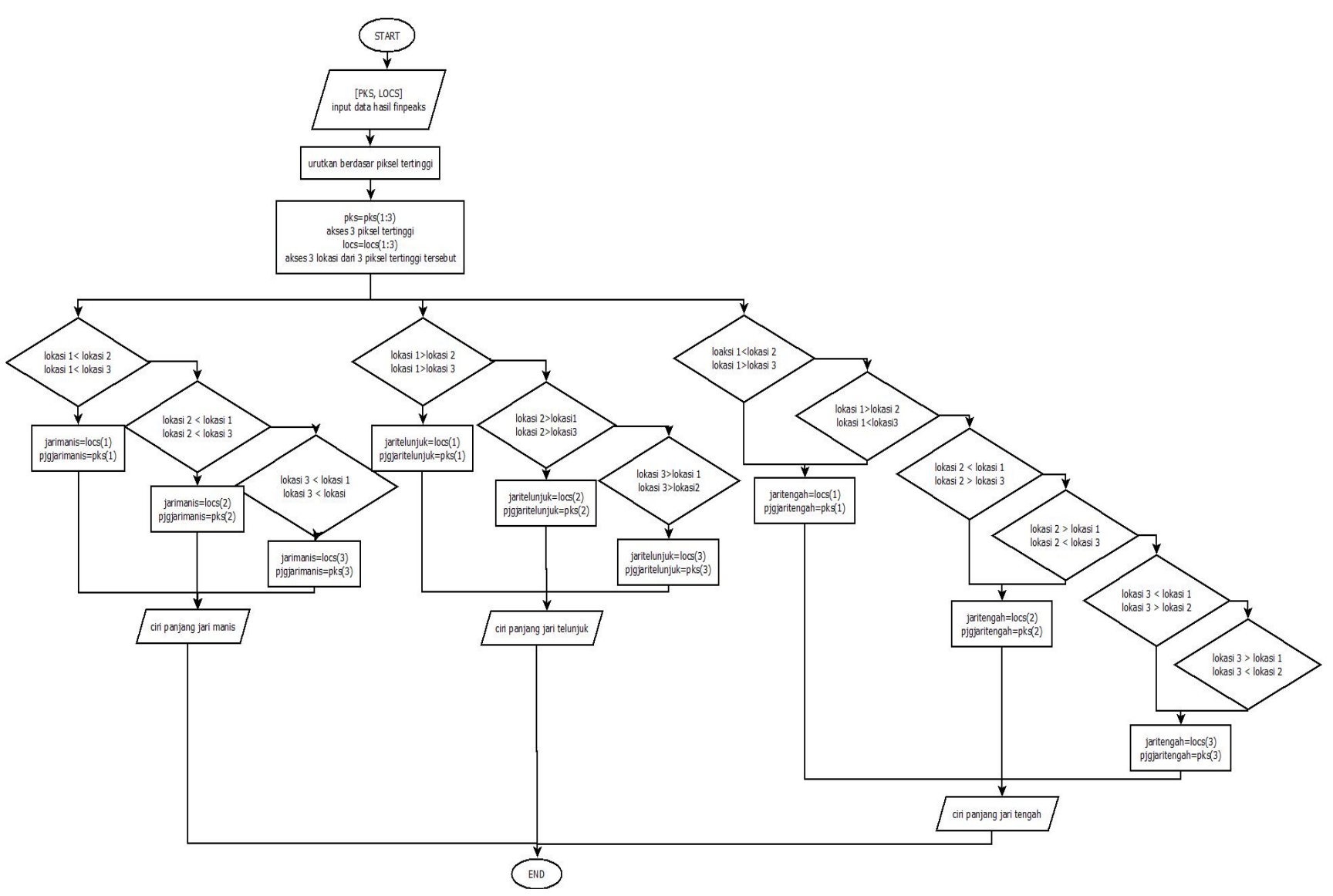

Berdasar citra biner hasil thresholding, ditentukan ciri-ciri geometri punggung tangan yaitu luas punggung tangan, lebar punggung tangan $\left(X_{1}\right)$, tinggi jari jari manis $\left(X_{2}\right)$, tinggi jari tengah $\left(X_{3}\right)$, dan tinggi jari telunjuk $\left(X_{4}\right)$. Hasil ekstraksi ciri akan divektorkan dan disimpan ke dalam database sebagai ciri. Gambar 5 memperlihatkan diagram alir untuk menemukan tinggi 3 jari, yaitu jari manis, jari tengah dan jari telunjuk.

Gambar 5. Diagram alir untuk ekstraksi ciri tingi jari tangan

Identifikasi personal dilakukan menggunakan LVQ sebagai classifier. Dalam hal ini input LVQ berupa lima ciri geometri yang diekstraksi dari citra punggung tangan kiri. Arsitektur LVQ yang digunakan diperlihatkan pada Gambar 6.

\section{HASIL DAN PEMBAHASAN}

Pada penelitian ini digunakan total 105 data citra punggung tangan kiri dari 7 kelas yang berbeda yang disimpan dengan ekstensi JPG, 70 data digunakan untuk data pelatihan, dan 35 data untuk data pengujian.

Menggunakan Gambar 1 sebagai data citra, Gambar 7 memperlihatkan hasil preprosesingnya.
Proses ekstraksi ciri dilakukan menggunakan citra biner hasil thresholding. Terdapat 5 ciri yang diekstrak, yaitu: luas punggung tangan, lebar punggung tangan, tinggi jari manis, tinggi jari tengah, dan tinggi jari telunjuk. Luas punggung tangan ditentukan berdasar jumlah piksel yang berwarna putih dan lebar punggung tangan ditentukan dengan menemukan jumlah piksel berwarna putih yang terbanyak pada pada setiap baris citra. Tiga ciri yang lain yang terkait tinggi jari ditentukan dengan pencarian local maxima seperti diperlihatkan pada Gambar 8 . 


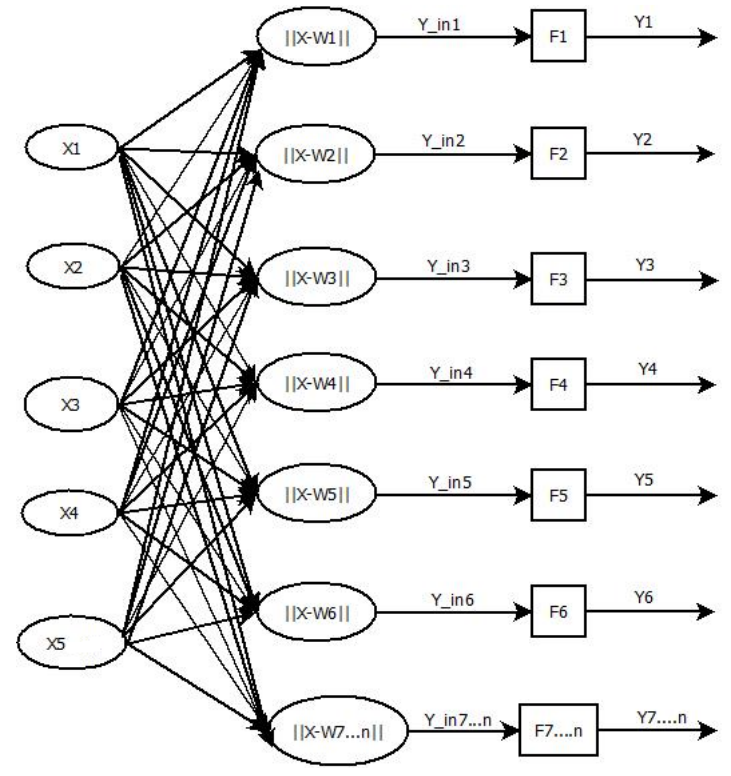

Gambar 6. Arsitektur LVQ

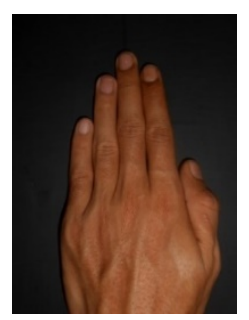

(a)

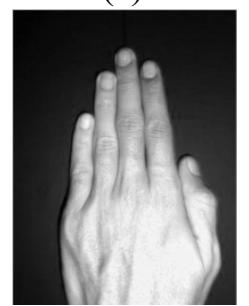

(c)

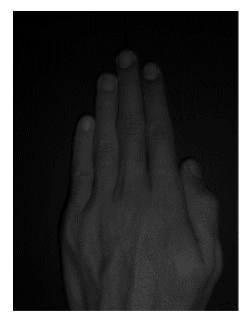

(b)

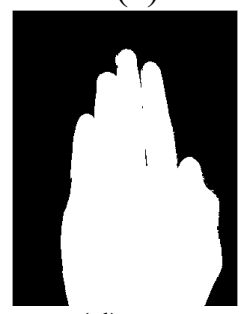

(d)

Gambar 7. Hasil preprosesing (a) Citra ukuran 400x300 piksel, (b) Citra grayscale, (c) Citra hasil contrast stretching, (d) Citra hasil thresholding

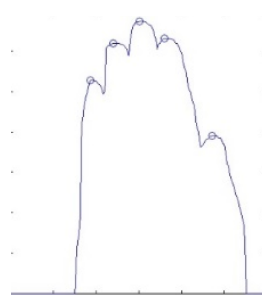

Gambar 8. Pencarian local maxima untuk menentukan tinggi jari

Setelah semua local maxima ditemukan, akan dihasilkan vektor yang menunjukkan jumlah piksel dan lokasinya. Dari vektor tersebut dipilih 3 lokasi yang memiliki jumlah piksel terbanyak untuk kemudian ditentukan lokasi dari jari manis, jari tengah dan jari telunjuk.

Berikut ini adalah salah satu contoh vektor ciri hasil ekstraksi.

$$
\mathrm{V}_{\text {ciri }}=\left[\begin{array}{lllll}
54175 & 215 & 349 & 329 & 332
\end{array}\right]
$$

Dengan setiap ciri dinyatakan dalam satuan piksel; elemen pertama adalah luas punggung tangan, elemen kedua adalah lebar punggung tangan, elemen ketiga dalah tinggi jari manis, elemen ke-empat adalah tinggi jari tengah, dan elemen ke-lima adalah tinggi jari telunjuk.

Hasil ekstraksi ciri dari 70 data citra yang digunakan untuk pelatihan, tujuh vektor ciri diantaranya dipilih secara acak (satu untuk setiap kelas) untuk digunakan sebagai bobot awal pelatihan jaringan LVQ.

$$
\text { Bobot_awal }=\left[\begin{array}{lllll}
54206 & 215 & 349 & 328 & 332 \\
40250 & 176 & 290 & 313 & 297 \\
46094 & 190 & 320 & 343 & 319 \\
50004 & 214 & 327 & 315 & 315 \\
49232 & 197 & 325 & 337 & 317 \\
48116 & 196 & 312 & 334 & 321 \\
44811 & 192 & 300 & 321 & 299
\end{array}\right]
$$

Pelatihan jaringan LVQ dilakukan menggunakan nilai $\alpha$ dan dec $\alpha$ yang bervariasi, dengan $\alpha=0,1 ; 0,01 ; 0,001 ; 0,0001 ; 0,00001$ dan $\operatorname{dec} \alpha=0,1 ; 0,25 ; 0,5 ; 0,75$. Gambar 9 memperlihatkan grafik persentase kinerja pelatihan jaringan LVQ dan Gambar 10 memperlihatkan jumlah iterasi dalam setiap proses pelatihan.

\section{Persentase Kinerja Pelatihan}

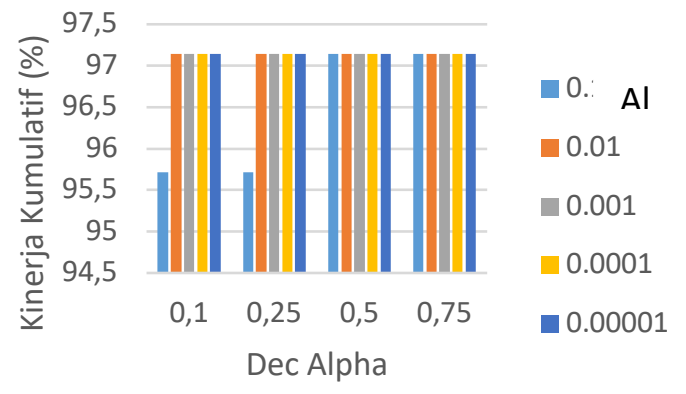

Gambar 9. Persentase kinerja pelatihan jaringan LVQ untuk berbagai kombinasi parameter 


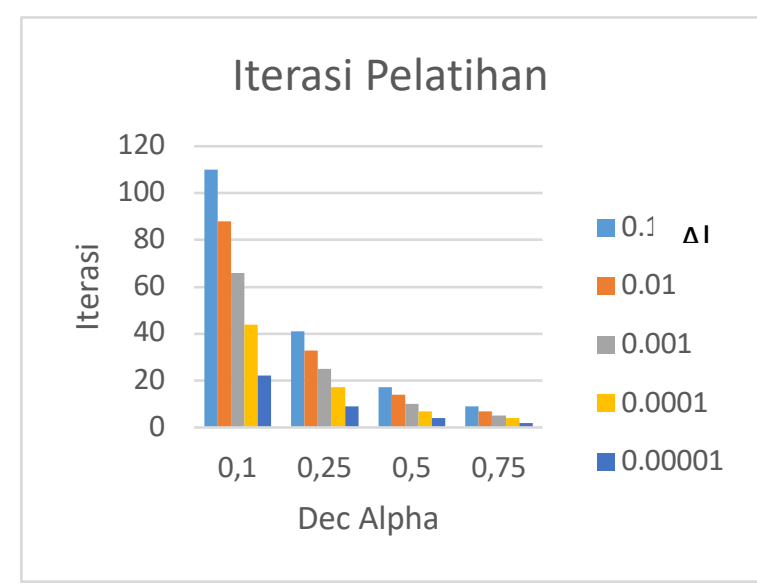

Gambar 10. Iterasi pelatihan jaringan LVQ

Hasil pelatihan menunjukkan bahwa kinerja pelatihan terendah adalah $95,71 \%$ dengan parameter $(\alpha=0,1$ dan dec $\alpha=0,1)$ dan parameter $(\alpha=0,25$ dan dec $\alpha=0,1)$. Kombinasi nilai parameter selain kombinasi tersebut menghasilkan kinerja pelatihan setinggi 97,14\% dan nilai ini merupakan kinerja tertinggi yang diperoleh dalam penelitian ini.

Untuk pengujian dengan data baru (35 data) dipilih hasil pelatihan dengan parameter $(\alpha$ $=0,01$ dan dec $\alpha=0,1)$ yang menghasilkan kinerja 97,14\% setelah iterasi ke-88 dan bobot akhir yang diperoleh sebagai berikut.

Bobot_akhir $=\left[\begin{array}{lllll}54183 & 214 & 348 & 330 & 323 \\ 40041 & 174 & 289 & 313 & 296 \\ 46031 & 189 & 320 & 342 & 323 \\ 49905 & 214 & 321 & 316 & 314 \\ 49251 & 196 & 317 & 336 & 321 \\ 48104 & 196 & 312 & 333 & 321 \\ 44976 & 192 & 300 & 320 & 299\end{array}\right]$

Hasil pengujian dengan 35 data baru menghasilkan kinerja setinggi $85,71 \%$.

\section{KESIMPULAN}

Kesimpulan yang dapat diambil dari penelitian identifikasi personal berdasarkan geometri citra punggung tangan kiri menggunakan metode Learning Vector Quantization adalah sebagai berikut.

1. Identifikasi personal berdasarkan geometri citra punggung tangan kiri menggunakan metode learning vector quantization menggunakan ciri luas tangan, lebar tangan, tinggi jari manis, tinggi jari tengah dan tinggi jari telunjuk.

2. Hasil pengujian pengenalan identitas personal berdasarkan geometri citra punggung tangan kiri mencapai kinerja tertinggi $85,71 \%$.

\section{DAFTAR PUSTAKA}

Ahmad, Usman. (2005). Pengolahan Citra Digital \& Teknik Pemogramannya, Graha Ilmu Yogyakarta

Andari, R.A., (2014). Analisis Sistem Verifikasi Dengan Menggabungkan Biometrika Telapak Tangan dan Geometri Tangan, Sekolah Tinggi Manajemen Informatika Dan Komputer AMIKOM [skripsi], Yogyakarta.

Kadir, Abdul. (2013). Dasar Pengolahan Citra dengan Delphi, Penerbit Andi Yogyakarta

Kadir, Abdul. (2013). Teori dan Aplikasi Pengolahan Citra, Penerbit Andi Yogyakarta

Kusumadewi, Sri. Membangun Jaringan Syaraf Tiruan Menggunakan Matlab \& Excel Link, Penerbit Graha Ilmu Yogyakarta.

Kusumadewi, Sri. (2003). Artificial Intellegence (Teknik dan Aplikasinya), Graha Ilmu Jogjakarta.

Munir, Rinaldi. (2004). Pengoahan Citra Digital dengan Pendekatan Algoritmik, Penerbit Informatika Bandung.

Perwitasari. (2012). Arsitektur LVQ. Diakses 21 Oktober 2014, dari: http://perwitasari-f1-fst08.web.unair.ac.id/.

Prastyo, Eko. (2011). Pengolahan Citra Digitan dengan Aplikasinya menggunakan Matlab, Penerbit Andi Yogyakarta

Putra, Darma. (2009). Pengolahan Citra Digital, Penerbit Andi Yogyakarta

Resmana Lim, Santoso (2003). Verifikasi Personal Berdasarkan Bentuk Geometri Tangan dengan Metode Filter Gabor [skripsi], Universitas Kristen Petra, Surabaya.

Satriyanto, Edi; Mohammad Syafi'i; Ari Hanggara (2009), Penerapan LVQ Neural Network pada Absensi Jarak Jauh Menggunakan Geometri Tangan Secara Online [skripsi], Institut Teknologi Sepuluh November, Surabaya.

Siswanto, Antonius; Pernantin Tarigan, Fahmi (2003), Perancangan Sistem Verifikasi Biometrik Tangan Tanpa Kontak Dengan Ukuran Geometri Relatif [skripsi], Universitas Sumatera Utara, Medan.

Suprapto (2011), Pengenalan Geometri Tangan Dengan Metode Neural Network Kohonen SOM [skripsi], Pelita Teknologi, Tegal.

Susilawati, Indah (2014), Penentuan Diameter Buah Jeruk Menggunakan Pengolahan 
Citra Digital, Universitas Mercu Buana

Yogyakarta, Yogyakarta, Jurnal

ORBITH.

Wikipedia. (2014). Jaringan Syaraf Tiruan. Diakses 20 Oktober 2014, dari: http://id.wikipedia.org/wiki/Jaringan_sa raf_tiruan. 
20 Jurnal Multimedia \& Artificial Intelligence, Volume 2, Nomor 1, Februari 2018 